Disponível em

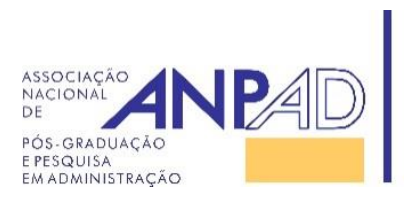

http://www.anpad.org.br/rac

RAC, Rio de Janeiro, v. 21, n. 5, art. 5,

pp. 685-709, Setembro/Outubro, 2017

http://dx.doi.org/10.1590/1982-7849rac2017160281

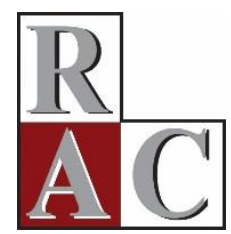

$((c))$ EY

\title{
Fatores Determinantes da Aprendizagem Organizacional para a Inovação Ambiental: Um Estudo Multicaso
}

Determinant Factors of Organizational Learning for Environmental Innovation: A Multicase Study

\author{
Rafael Ricardo Jacomossi ${ }^{1}$ \\ Jacques Demajorovic $^{1}$ \\ Centro Universitário $\mathrm{FEI}^{1}$
}

Artigo recebido em 26.09.2016. Última versão recebida em 22.04.2017. Aprovado em 19.05.2017. Publicado online em 20.06.2017. 


\title{
Resumo
}

Conforme as questões ambientais orientam as ações das empresas por meio de sua agenda de inovação, a aprendizagem organizacional surge como importante elemento de análise. Sugere-se que as noções de aprendizagem organizacional e aprendizagem para a sustentabilidade devam convergir, estabelecendo-se como antecedentes do próprio processo de inovação ambiental e denotando, a partir deste ponto, um novo campo de análise - o da Aprendizagem Organizacional para a Inovação Ambiental. Este trabalho tem como objetivo identificar os indutores que determinam a aprendizagem organizacional para a inovação ambiental. Para tanto, foi elaborado um modelo conceitual de análise que foi aplicado por meio de um estudo multicaso em três empresas. Das diversas variáveis analisadas, a regulação, o papel do empreendedor, o trabalho de Pesquisa \& Desenvolvimento (P\&D) em redes e a existência de um processo de gestão ambiental se mostraram influentes para a consolidação do processo de aprendizagem. Infere-se que as influências das variáveis do processo de aprendizagem organizacional para a inovação ambiental diferem quanto à intensidade em função do modelo de negócio adotado, do grau de autonomia dos gerentes, do tipo de educação ambiental recebido pelos funcionários, do ambiente cultural e do perfil do empreendedor.

Palavras-chave: aprendizagem organizacional; aprendizagem para sustentabilidade; inovação ambiental.

\begin{abstract}
As environmental issues guide the actions of companies through their innovation agenda, organizational learning emerges as an important element of analysis. It has been suggested that the concepts of organizational learning and learning for sustainability must converge in order to establishing themselves as antecedents of the environmental innovation process, and from there a new field of analysis - Organizational Learning for Environmental Innovation. This work aims to identify inducers that determine organizational learning for environmental innovation. A conceptual analysis model was developed and applied through a multicase study of three companies. As analyzed, the most important variables for the consolidation of the learning process were regulation, entrepreneurs, Research \& Development (R\&D) networks and the existence of an environmental management process. These are all very important for learning process consolidation. It is inferred that organizational learning process variables for environmental innovation differ in intensity depending on the business model adopted, the degree of manager autonomy, the type of employee environmental education, the cultural environment and entrepreneur profile.
\end{abstract}

Key words: organizational learning; learning for sustainability; environmental innovation. 


\section{Introdução}

Os estudos organizacionais evidenciam o papel da aprendizagem organizacional como antecedente do processo de inovação. No entanto, estes processos de aprendizagem, baseados em uma racionalidade dominante que enfatiza os ganhos econômicos em detrimento da redução de impactos ambientais, denotam um processo de inovação limitado e pouco eficaz para lidar com os riscos socioambientais gerados (Faustenhammer \& Gössler, 2011). A inovação ambiental emerge nesse contexto, tanto no campo acadêmico como empresarial, como uma estratégia para conciliar duas forças aparentemente antagônicas: competividade e mitigação de danos ambientais (Bossle, Barcellos, Vieira, \& Sauv, 2016; Jacomossi, Demajorovic, Santiago, \& Bernardes, 2016). Como resultado, diversas pesquisas têm focado os determinantes da inovação ambiental, destacando-se fatores internos (perfil do empreendedor e do gerente; a existência de uma cultura organizacional que abarque a dimensão ambiental; a importância da existência de um departamento da Pesquisa \& Desenvolvimento [P\&D]) e fatores externos (papel da regulação; interação com universidades; trabalho em parceria com fornecedores) (Bossle et al., 2016; Carrillo-Hermosilla, Del Río, \& Könölla, 2010; Halila \& Rundquist, 2011; Jacomossi et al., 2016; Marinescu, Ciocoiu, \& Cicea, 2015; Ramus \& Steger, 2000; Shu, Zhou, Xiao, \& Gao, 2016; Zhang et al., 2013).

Em outra vertente dos estudos organizacionais, cresce a importância do debate acerca dos fatores indutores da aprendizagem para a sustentabilidade, sobretudo pela necessidade de as organizações lançarem um novo olhar para a forma de como aprendem e também de fornecerem repostas aos desafios ambientais e sociais (Ângelo, Jabbour, \& Galina, 2012; Edwards, 2009; Espinosa \& Porter, 2011; Jacobi, Toledo, \& Grandisoli, 2016; Jamali, 2006; Porter \& Lindle, 1995).

Contudo, quando se olha para as áreas da Aprendizagem Organizacional como antecedente do processo de inovação, da Aprendizagem para a Sustentabilidade como uma condição para que as empresas incorporem novos valores ambientais e da própria Inovação Ambiental como resultado de um processo de aprendizagem, percebe-se que essas áreas possuem elementos de convergência. Fatores indutores para o processo de aprendizagem organizacional, aprendizado para sustentabilidade e inovação ambiental, ora são semelhantes, ora são complementares, podendo fornecer elementos para um campo emergente do conhecimento denominado Aprendizagem Organizacional para a Inovação Ambiental.

Nesse contexto propõe-se duas questões de pesquisa: Quais são os elementos que influenciam o processo de aprendizado organizacional para inovação ambiental? E quais destes fatores induzem a maiores níveis de aprendizagem organizacional para a promoção desse tipo de inovação? Nessa direção, o objetivo desta pesquisa é identificar os fatores que induzem a um processo de aprendizagem organizacional para a inovação ambiental. Para tanto, este trabalho propõe e aplica, em três estudos de caso, um modelo conceitual de análise para avaliar práticas de aprendizagem organizacional em empresas que estejam empenhadas em incorporar a agenda ambiental em seus processos de inovação.

\section{Revisão Teórica}

\section{Aprendizagem organizacional}

Para Kuntz e Gomes (2012), a aprendizagem nas organizações ocorre quando se verificam mudanças que se relacionam a atender às expectativas dos clientes internos, externos e de outras variáveis ambientais. Argote e Miron-Spektor (2011) postulam que a aprendizagem organizacional é decorrente da aquisição de experiências e está relacionada a aspectos cognitivos ou comportamentais, que podem ocorrer por conhecimentos tácitos, explícitos ou pela combinação de ambos, desencadeando processos que geram mudanças. A aprendizagem, no entanto, não ocorre de maneira contínua e permanente, pois segundo Santos e Sampaio (2016), esses eventos decorrem da necessidade e da 
disponibilidade de se trocar experiências e aprendizados. A seguir se apresenta, por meio da Tabela 1, diversos trabalhos que apontam o caráter interdisciplinar da aprendizagem e as características organizacionais e individuais que podem estimular este processo.

Tabela1

\section{Elementos e Características da Aprendizagem Organizacional}

\begin{tabular}{|c|c|c|}
\hline Elementos & Características & Autores \\
\hline Formação de memórias & $\begin{array}{l}\text { O indivíduo possui a capacidade de } \\
\text { construir um pensamento crítico e } \\
\text { reflexivo e, em seguida, reinterpretar seu } \\
\text { mundo. }\end{array}$ & $\begin{array}{l}\text { Walsh e Ungson (1991); Argyris e Schön } \\
\text { (1978); Bandura (1977); Soparnot (2011); } \\
\text { Becker (2010); Kuntz e Gomes (2012), } \\
\text { Ferreira e Godoy (2015); Castañeda (2015). }\end{array}$ \\
\hline Metas & $\begin{array}{l}\text { Mecanismos de reflexão, autorregulação } \\
\text { e de capacidade de agência, em que os } \\
\text { indivíduos se direcionam aos seus } \\
\text { objetivos por intermédio de processos de } \\
\text { avaliação. }\end{array}$ & Bandura (1977); Argyris e Schön (1991). \\
\hline $\begin{array}{l}\text { Redes de interação com } \\
\text { ambiente externo }\end{array}$ & $\begin{array}{l}\text { A organização interage com o ambiente } \\
\text { externo, propiciando um ambiente de } \\
\text { aprendizagem. }\end{array}$ & $\begin{array}{l}\text { Ichijo e Nonaka (2007); Kuntz e Gomes } \\
\text { (2012); Nogueira e Odelius (2015); Santos e } \\
\text { Sampaio (2016); Ayres e Popadiuk (2016). }\end{array}$ \\
\hline Papel do gerente & $\begin{array}{l}\text { O gerente age como disseminador de um } \\
\text { clima propício para a aprendizagem, além } \\
\text { de agir como facilitador nesse processo. }\end{array}$ & $\begin{array}{l}\text { Argyris e Schön (1991); Fiol e Lyles } \\
\text { (1985); Ichijo e Nonaka (2007); Bandura } \\
\text { (1977). }\end{array}$ \\
\hline Fatores motivacionais & $\begin{array}{l}\text { O processo de aprendizagem é } \\
\text { impulsionado por fatores motivacionais } \\
\text { ligados à cognição, à afetividade e à } \\
\text { sociabilidade. }\end{array}$ & Piaget (1978); Santos e Sampaio (2016). \\
\hline
\end{tabular}

Nota. Elaborada pelos autores.

Percebe-se que as dimensões explicitadas na Tabela 1 se situam tanto em esferas subjetivas do indivíduo, como a formação de memórias, fatores motivacionais e a existência de metas, quanto em esferas decorrentes de processos de interação, como a atuação do gerente e os contatos com redes externas. Outros elementos também se apresentam importantes ao processo de aprendizagem organizacional, como a própria cultura de aprendizado, uma abordagem estratégica que contemple a necessidade de políticas de aprendizagem nas organizações, a formação das pessoas e o suporte organizacional (Beyene, Shi, \& Wu, 2016; Castañeda, 2015).

Estudar o processo de aprendizagem organizacional, segundo Nogueira e Odelius (2015), traz muitos desafios, sobretudo pela multiplicidade de dimensões e variáveis existentes. Recentemente os estudos têm avançado para que este processo de aprendizado contribua com melhorias também no desempenho ambiental e social das organizações, e não somente com ganhos econômicos.

\section{Aprendizagem para a sustentabilidade}

Para Siebenhüner e Arnold (2007), há uma percepção por parte dos defensores da sustentabilidade de que ela deve ser trabalhada nas organizações como quadro subjacente ao da aprendizagem organizacional, já que ambas possuem fluxos e modelos mentais comuns. Velázquez, Esquer e Munguía (2011) comentam que uma organização que aprende para a sustentabilidade é caracterizada por gerar um conhecimento que modifique suas práticas de forma a diminuir e/ou suprimir os riscos relativos às suas operações. esquisas nesta temática, no entanto, são ainda incipientes, conforme estudo bibliométrico desenvolvido por Cortês e Rodrigues (2016), ainda que seja possível identificar na 
literatura um conjunto de fatores que estimulam a aprendizagem para sustentabilidade nas organizações, conforme Tabela 2.

Tabela 2

Fatores Indutores do Processo de Aprendizagem para a Sustentabilidade

\begin{tabular}{|c|c|c|}
\hline Elementos & Características & Autores \\
\hline Identidade cultural & $\begin{array}{l}\text { Valores e normas que enaltecem a } \\
\text { emergência de um pensamento sistêmico } \\
\text { e direcionado para a sustentabilidade. }\end{array}$ & $\begin{array}{l}\text { Jamali (2006); Edwards (2009); } \\
\text { Stoughton e Ludema (2012); Velázquez } \\
\text { et al. (2011); Ceschin (2013); Jacobi, } \\
\text { Toledo e Grandisoli (2016). }\end{array}$ \\
\hline Agente individual & $\begin{array}{l}\text { O indivíduo, por meio de processos de } \\
\text { reflexão com base nas suas capacidades } \\
\text { cognitivas, forma modelos mentais que } \\
\text { direcionam suas ações para a } \\
\text { sustentabilidade. }\end{array}$ & $\begin{array}{l}\text { Siebenhüner e Arnold (2007); Köhler et } \\
\text { al. (2013); Jamali (2006); Dlouhá, Barton } \\
\text { e Janousková (2013); Jacomossi, Morano } \\
\text { e Barrichello (2014); Botes, Low e } \\
\text { Chapman (2014). }\end{array}$ \\
\hline Educação e treinamento & $\begin{array}{l}\text { Processos de educação corporativa para a } \\
\text { sustentabilidade que abarquem a } \\
\text { discussão de temas mais amplos, tais } \\
\text { como: aquecimento global, acidentes } \\
\text { químicos, recursos renováveis e não } \\
\text { renováveis, gestão de riscos. }\end{array}$ & $\begin{array}{l}\text { Coleman (2013); Fenwick (2007); } \\
\text { Dlouhá et al. (2013); Ângelo, Jabbour e } \\
\text { Galina (2012); Bevis (2011). }\end{array}$ \\
\hline $\begin{array}{l}\text { Interação entre os níveis } \\
\text { organizacionais }\end{array}$ & $\begin{array}{l}\text { Alinhamento estratégico entre os diversos } \\
\text { níveis organizacionais, representado por } \\
\text { políticas top-down e bottom-up. }\end{array}$ & $\begin{array}{l}\text { Espinosa e Porter (2011); Zhang et al. } \\
\text { (2013). }\end{array}$ \\
\hline Perfil do empreendedor & $\begin{array}{l}\text { A visão de mundo do empresário e/ou } \\
\text { alto executivo com questões ligadas à } \\
\text { sustentabilidade é extrapolada para o } \\
\text { restante da organização. }\end{array}$ & $\begin{array}{l}\text { Zhang et al. (2013); Liddle e El-Kafafi } \\
(2010) .\end{array}$ \\
\hline Sistemas de recompensa & $\begin{array}{l}\text { A existência de sistemas de recompensas } \\
\text { incentiva a criação de ambientes de } \\
\text { aprendizagem. }\end{array}$ & $\begin{array}{l}\text { Ramus e Steger (2000); Prugsamatz } \\
(2010) \text {. }\end{array}$ \\
\hline Excelência operacional & $\begin{array}{l}\text { Normalmente, empresas excelentes têm } \\
\text { melhores performances ambientais. }\end{array}$ & $\begin{array}{l}\text { Gavronski, Klassen, Vachon e } \\
\text { Nascimento (2012); Loukas (2012); } \\
\text { Stoughton e Ludema (2012). }\end{array}$ \\
\hline Papel do gerente & $\begin{array}{l}\text { A liderança gerencial estimula os } \\
\text { indivíduos a aprenderem para a } \\
\text { sustentabilidade. }\end{array}$ & $\begin{array}{l}\text { Stoughton e Ludema (2012); Ramus e } \\
\text { Steger (2000); Meng (2014). }\end{array}$ \\
\hline Suporte público/privado & $\begin{array}{l}\text { A existência de instituições que apoiam e } \\
\text { estimulam atividades direcionadas a } \\
\text { desenvolver mecanismos para a } \\
\text { sustentabilidade promove ambientes de } \\
\text { aprendizagem. }\end{array}$ & $\begin{array}{l}\text { Klewitz, Zeien e Hansen (2012); Jacobi } \\
\text { et al. (2016). }\end{array}$ \\
\hline Regulação & $\begin{array}{l}\text { A existência de uma legislação que atue } \\
\text { com mecanismos de controle da poluição } \\
\text { e de outros efeitos deletérios, como a } \\
\text { produção de resíduos. }\end{array}$ & $\begin{array}{l}\text { El-Kafafi e Liddle (2011); Gavronski et } \\
\text { al. (2012); Barla (2007). }\end{array}$ \\
\hline Redes de colaboração & $\begin{array}{l}\text { A participação em redes externas de } \\
\text { cooperação com múltiplos stakeholders } \\
\text { promove ambientes de aprendizagem. }\end{array}$ & $\begin{array}{l}\text { Ceschin (2013); Dlouhá et al. (2013); } \\
\text { Fenwick (2007); Prugsamatz (2010); } \\
\text { Liddle e El-Kafafi (2010); Styles, } \\
\text { Schoenberger e Galvez-Martos (2012); } \\
\text { Jacobi et al. (2016). }\end{array}$ \\
\hline
\end{tabular}

Nota. Elaborada pelos autores.

RAC, Rio de Janeiro, v. 21, n. 5, art. 5, pp. 685-709, Setembro/Outubro, 2017, www.anpad.org.br/rac (ac) 
A aprendizagem para sustentabilidade amplia os elementos identificados na aprendizagem organizacional no que se refere a fatores internos e externos. Destaca-se, aqui, além de fatores internos como programas de educação específicos para este fim, o papel do empreendedor e o nível de interação entre as áreas, assim como o papel da legislação ambiental e do suporte público e privado para a geração de conhecimento. Argumenta-se que esses elementos são fundamentais no desenvolvimento do processo de inovação ambiental.

\section{Inovação ambiental}

Nos termos de Kammerer (2009), a inovação ambiental é toda inovação surgida em nível organizacional que transmita externalidades positivas ao meio ambiente, contemplando mudanças oriundas das atividades organizacionais que visem, sobretudo, a reduzir os impactos de sua operação. Assim, a inovação verde, ambiental ou ecoinovação podem ser definidas como novos processos, técnicas, práticas, sistemas e produtos que reduzam o impacto ambiental (Beise \& Rennings, 2005).

A fim de sintetizar as contribuições da literatura e expor as características e determinantes da temática da inovação ambiental, é apresentada a Tabela 3:

Tabela 3

\section{Dimensões da Inovação Ambiental}

\begin{tabular}{|c|c|c|}
\hline Dimensão & Características & Autores \\
\hline Usuário & $\begin{array}{l}\text { A aceitação, por parte dos usuários, em } \\
\text { função dos benefícios que a utilização do } \\
\text { produto representa, constitui um importante } \\
\text { indutor de inovação ambiental. }\end{array}$ & $\begin{array}{l}\text { Ramus e Steger (2000); Liddle e El-Kafafi } \\
\text { (2010); Carrillo-Hermosilla, Del Río e Könölla } \\
\text { (2010); Horbach, Rammer e Rennings (2012); } \\
\text { Marinescu, Ciocoiu e Cicea (2015). }\end{array}$ \\
\hline Gestão Ambiental & $\begin{array}{l}\text { Pode-se traduzir por programas de } \\
\text { gerenciamento, como ISO 14001, no uso } \\
\text { de tecnologia de prevenção e controle e } \\
\text { de outras ferramentas de gestão que } \\
\text { melhorem a performance ambiental. }\end{array}$ & $\begin{array}{l}\text { Ângelo et al. (2012); Beise e Rennings } \\
\text { (2005); Velázquez et al. (2011); Gavronski } \\
\text { et al. (2012); Shu, Zhou, Xiao e Gao (2016). }\end{array}$ \\
\hline Pensamento estratégico & $\begin{array}{l}\text { Caracteriza-se pela introdução de } \\
\text { preocupações ambientais no escopo } \\
\text { estratégico da organização, que inclusive } \\
\text { se encontra declarado na missão e visão } \\
\text { do negócio e desdobrado para todos os } \\
\text { níveis organizacionais. }\end{array}$ & $\begin{array}{l}\text { Klewitz et al. (2012); Cheng, Yang e Sheu } \\
\text { (2014); De Marchi (2012); Hansen e Klewitz } \\
\text { (2012); El-Kafafi e Liddle (2011); Bevis } \\
\text { (2011); Brasil, Abreu, Silva e Leocádio } \\
\text { (2016); Bossle, Barcellos, Vieira e Sauv } \\
\text { (2016). }\end{array}$ \\
\hline $\begin{array}{l}\mathrm{P} \& \mathrm{D} \text { disseminado em } \\
\text { redes de cooperação }\end{array}$ & $\begin{array}{l}\text { Os esforços cooperados entre empresas e } \\
\text { redes de clientes e fornecedores situados } \\
\text { numa mesma cadeia produtiva, além de } \\
\text { universidades, impelem que se busque } \\
\text { soluções compartilhadas entre esses atores. }\end{array}$ & $\begin{array}{l}\text { Yarahmadi e Higgins (2012); De Marchi } \\
\text { (2012); Berrone, Fosfuri e Gelabert (2013); } \\
\text { Santolaria, Solà, Gasol, Morales-Pinzón e } \\
\text { Rieradevall (2012); Köhler et al. (2013). }\end{array}$ \\
\hline Regulação & $\begin{array}{l}\text { A legislação se apresenta como forte } \\
\text { indutor à introdução de inovações } \\
\text { ambientais de produtos. }\end{array}$ & $\begin{array}{l}\text { Ceschin (2013); Yarahmadi e Higgins (2012); } \\
\text { De Marchi (2012); Berrone et al. (2013), } \\
\text { Marinescu et al. (2015); Jacomossi, } \\
\text { Demajorovic, Santiago e Bernardes (2016). }\end{array}$ \\
\hline
\end{tabular}

Nota. Elaborada pelos autores.

Assim como o processo de inovação tradicional se relaciona com processos de aprendizagem organizacionais, o mesmo ocorre com a inovação ambiental, que carrega adicionalmente determinantes do processo de aprendizagem para a sustentabilidade. Dessa forma, sugere-se um modelo que abarque todas as similitudes dessas áreas e que sirva para avaliar processos de aprendizagem para a inovação ambiental nas organizações. 


\section{Áreas de convergência entre aprendizagem organizacional, aprendizagem para a sustentabilidade e inovação ambiental}

Uma vez que as abordagens apresentadas anteriormente (Aprendizagem Organizacional, Aprendizagem para a Sustentabilidade e Inovação Ambiental) possuem diversas similitudes, far-se-á uma tentativa de convergir suas principais características e determinantes em torno de elementos comuns entre as novas categorias, de acordo com a Tabela 4:

Tabela 4

\section{Categorias Referentes à Aprendizagem Organizacional para a Inovação Ambiental}

\begin{tabular}{l} 
Nova Categoria / Origem / \\
Indicador \\
\hline Categoria Memórias \\
Originada de: \\
Aprendizagem \\
Organizacional \\
(Formação de memórias, \\
Valores e Identidade \\
Cultural e Aprendizagem \\
Grupal); Aprendizagem \\
para a Sustentabilidade \\
(Identidade cultural, Agente \\
individual e Dinâmica de \\
grupos).
\end{tabular}

recompensas. Esses elementos propiciam ambientes de aprendizagem para a inovação ambiental.

\section{Autores}

São os processos cognitivos dos indivíduos por meio de suas experiências de vida acumuladas e o modo como o exercício de reflexão crítica pode induzir à reinterpretação da sua própria realidade, além da história acumulada da empresa. Influencia também, nesse processo, a cultura da organização que é decorrente de sua própria declaração de missão/visão, hábitos, valores, bem como a ação dos grupos de trabalho, além de sistemas de

Walsh e Ungson (1991); Argyris e Schön (1978); Cangelosi e Dill (1965); Berger e Luckmann (1985); Bandura (1977); Soparnot (2011); Becker (2010); Giddens (1991); Fiol e Lyles (1985); Antonello e Godoy (2010); Kuntz e Gomes (2012); Ichijo e Nonaka (2007); Senge (1990); Jamali (2006);

Edwards (2009); Stoughton e Ludema (2012); Velázquez et al. (2011); Ceschin (2013); Banerjee (2003); Siebenhüner e Arnold (2007); Köhler et al. (2013); Dlouhá et al. (2013); Prugsamatz (2010); Klewitz et al. (2012); Cheng et al. (2014); De Marchi (2012); Porter e Linde (1995); Hansen e Klewitz (2012); El-Kafafi e Liddle (2011); Bevis (2011); Argyris e Schön (1991); Piaget (1978); Argote e Miron-Spektor (2011); Ramus e Steger (2000); Prugsamatz (2010); Ferreira e Godoy (2015); Castañeda (2015); Jacobi et al. (2016); Jacomossi et al. (2014); Botes et al. (2014).

Categoria Gerente
Originada de:
Aprendizagem
Organizacional (Liderança,
Papel do gerente, Metas e
fatores motivacionais);
Aprendizagem para a
Sustentabilidade (Papel do
gerente, Sistemas de
recompensa).

\section{Categoria Educação \\ Ambiental}

Originada de:

Aprendizagem para a Sustentabilidade (Educação/ Treinamento)
O gerente exerce liderança sobre os Huber (1991); Fiol e Lyles (1985); indivíduos, propiciando ambientes de Bandura et al. (2008); Berger e Luckmann aprendizagem para a inovação ambiental.
(1985); Argyris e Schön (1991); Fiol e Lyles (1985); Ichijo e Nonaka (2007); Bandura (1977); Stoughton e Ludema (2012); Ramus e Steger (2000); Meng (2014).
Este indicador trata da importância de se discutir temas mais amplos, como aquecimento global, acidentes químicos, recursos renováveis e não renováveis, gestão de riscos, além de outros que propiciem ações que melhorem a performance ambiental da organização, formando um pensamento mais crítico/reflexivo e promovendo ambientes de aprendizagem.

Soares (2004); Claro (2008); Demajorovic (2003); Coleman (2013); Fenwick (2007); Dlouhá et al. (2013); Ângelo et al. (2012); Bevis (2011); Hansen e Klewitz (2012); Jacobi et al. (2016); Jacomossi et al. (2014). 


\section{Tabela 4 (continuação)}

\begin{tabular}{|c|c|}
\hline $\begin{array}{l}\text { Nova Categoria / Origem / } \\
\text { Indicador }\end{array}$ & Definição \\
\hline $\begin{array}{l}\text { Categoria Empreendedor } \\
\text { Originada de: } \\
\text { Aprendizagem para a } \\
\text { Sustentabilidade } \\
\text { (Perfil do empreendedor) }\end{array}$ & $\begin{array}{l}\text { A visão de mundo do empresário ou } \\
\text { executivo do topo da administração, } \\
\text { conferindo estruturas cognitivas } \\
\text { relacionadas às questões ambientais, } \\
\text { dissemina no ambiente um processo } \\
\text { sistêmico de aprendizagem que é } \\
\text { extrapolado para os níveis } \\
\text { hierarquicamente inferiores da } \\
\text { organização. }\end{array}$ \\
\hline
\end{tabular}

Categoria Gestão Ambiental

Originada de:

Aprendizagem para a
Sustentabilidade
(Excelência operacional);
Inovação Ambiental
(Gestão ambiental)

Empresas que dirigem suas atividades normatizadas tendem a alcançar melhores resultados, associando, portanto, a excelência operacional ao alcance de metas. Na maioria das vezes esses resultados são extrapolados para produtos e/ou processos ecoeficientes, com base em operações padronizadas e decorrentes também da existência de sistemas de gestão ambiental, o que propicia um ambiente de aprendizagem.

Categoria P\&D em Redes
Originada de:

Aprendizagem Organizacional (Redes de interação com o ambiente externo); Aprendizagem para a Sustentabilidade (Redes de colaboração, Suporte público/privado)

Inovação Ambiental (P\&D disseminado em redes de cooperação)
Atuação em P\&D colaborativo com universidades, fornecedores e institutos de pesquisa reforça o potencial de troca de experiências e conhecimentos, promovendo ambientes de aprendizagem.

\section{Autores}

Banerjee (2003); Zhang et al. (2013); Liddle e El-Kafafi (2010); Faustenhammer e Gössler (2011); Quist e Tukker (2013).

\begin{abstract}
Ângelo, Jabbour e Galina (2011);
Zhang et al. (2008); Kammerer (2009); Beise e Rennings (2005); Velázquez et al. (2011); Gavronski et al. (2012); Loukas (2012); Stoughton e Ludema (2012); Shu et al. (2016).
\end{abstract}

El-Kafafi e Liddle (2011); Yarahmadi e Higgins (2012); De Marchi (2012); Berrone et al. (2013); Santolaria et al. (2012); Köhler et al. (2013); Huber (1991); Forrester (1975); Ichijo e Nonaka (2007); Senge (1990); Kuntz e Gomes (2012); Ceschin (2013); Jamali (2006); Dlouhá et al. (2013); Fenwick (2007); Prugsamatz (2010); Styles et al. (2012); Nogueira e Odelius (2015); Santos e Sampaio (2016).

\begin{tabular}{ll}
\hline Categoria Regulação & A legislação atua como forte indutor \\
Originada de: & para um ambiente de aprendizagem \\
Aprendizagem para a & voltado à inovação ambiental, pois as \\
Sustentabilidade & organizações começam a atuar com \\
(Regulação); & vistas a controlar os efeitos deletérios de \\
Inovação Ambiental & suas atividades.
\end{tabular}

Ceschin (2013); El-Kafafi e Liddle (2011); Gavronski et al. (2012); Barla (2007); Yarahmadi e Higgins (2012); De Marchi (2012); Berrone et al. (2013); Ford, Steen e Verreynne (2014); Marinescu et al. (2015); Jacomossi et al. (2016). (Regulação)

\begin{tabular}{ll}
\hline Categoria Usuários de & $\begin{array}{l}\text { A aceitação por parte dos usuários de } \\
\text { produtos representa um importante } \\
\text { Produtos }\end{array}$ \\
$\begin{array}{l}\text { Originador de aprendizagem organizacional } \\
\text { para a inovação ambiental. }\end{array}$ \\
$\begin{array}{l}\text { Inovação Ambiental (P\&D } \\
\text { disseminado em redes de }\end{array}$ &
\end{tabular}

Ramus e Steger (2000); Liddle e ElKafafi (2010); Carrillo-Hermosilla et al. (2010); Horbach et al. (2012); Marinescu et al. (2015). cooperação)

Nota. Elaborada pelos autores.

Um desafio subsequente, após encontrar e conceituar as novas categorias de análise, foi o de agrupá-las em torno de temas centrais. Para tanto, foi proposta a construção de um modelo conceitual de análise, levando-se em consideração as contribuições de Cheetham e Chivers (1998), que propõem 
uma metodologia para a construção de modelos, enaltecendo a importância de se estabelecer "núcleos centrais". No presente estudo, a proposta ocorreu em torno dos seguintes núcleos: o enfoque de liderança, o enfoque cognitivo, o enfoque funcional e o enfoque externo.

Na elaboração da Figura 1, buscou-se agrupar os principais pontos levantados pela literatura e, em seguida, propor uma nova referência: a da aprendizagem organizacional para a inovação ambiental. Contudo, observou-se que algumas categorias possuem características semelhantes; assim, foram agrupadas em elementos de análises mais amplos. $\mathrm{O}$ modelo encontra-se aderente à perspectiva de Espinosa e Porter (2011), que comentam sobre a complexidade de modelos que se dedicam a estudar temas relacionados à sustentabilidade, devido aos inúmeros agentes e múltiplas relações de causalidade.

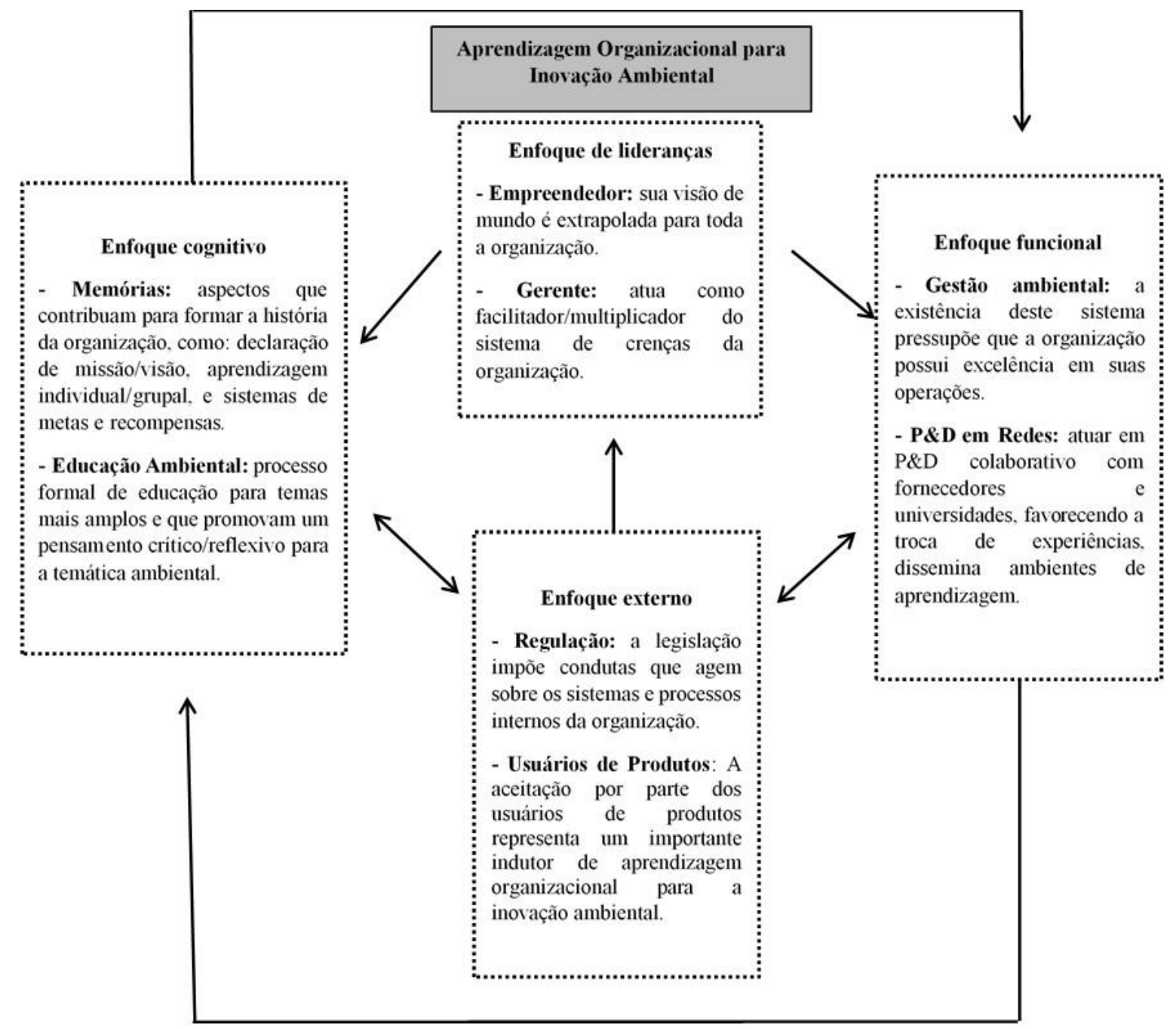

Figura 1. Proposição de Modelo Conceitual de Análise de Aprendizagem Organizacional para a Inovação Ambiental

Elaborada pelos autores por meio da convergência teórica entre as áreas da Aprendizagem Organizacional, Aprendizagem para a Sustentabilidade e Inovação Ambiental.

Isso posto, a proposta deste modelo parte da premissa de que a interação entre os elementos e suas respectivas categorias desencadeia processos de aprendizagem organizacional para a inovação ambiental. 


\section{Metodologia}

Para dar conta de responder às questões de pesquisa, optou-se por desenvolver uma pesquisa qualitativa de caráter exploratório-explicativa. A fim de se identificar os drivers do processo de aprendizagem organizacional para a inovação ambiental, considerando a pesquisa de campo, elegeu-se a estratégia de estudo de caso, pois esta metodologia permite realizar descrições detalhadas acerca de fenômenos pouco conhecidos, visando ao seu exame detalhado, e, a partir dessa análise, construir teorias (Eisenhardt, 1989).

Para o desenvolvimento do caso, foram escolhidas três empresas que se destacam em projetos de inovação ambiental, identificadas ficticiamente neste trabalho como: Alpha, Beta e Gama. Cabe frisar que essas empresas foram eleitas por indicação de profissionais que atuam na área de gestão ambiental, e que o principal critério de escolha recaiu sobre a relevância destas companhias nos mercados em que atuam, além de terem significativos projetos de inovação ambiental em seus respectivos portfólios, o que lhes assegura características de singularidade e exemplaridade apontadas por Yin (2005) para a seleção de casos. Além disso, o propósito da pesquisa foi explicado previamente a estas instituições de forma que suas participações se seguiram de maneira voluntária. A primeira é reconhecida mundialmente como precursora no desenvolvimento de um insumo verde para a indústria de rótulos adesivos. A segunda é uma startup americana presente em 23 países e com filial no Brasil, que atua na reciclagem de materiais de difícil reciclabilidade e sua reintrodução no processo produtivo. A terceira é líder brasileira no mercado de energia elétrica, tendo em seu portfólio de produtos vários projetos de geração de energia renovável.

O principal procedimento utilizado para a coleta de dados primários foi a técnica de entrevistas semiestruturadas. Neste caso, privilegiou-se gerar o máximo de flexibilidade aos entrevistados, decisão que, por si só, propiciou, em vários momentos, revelações importantes. Assim, algumas entrevistas foram realizadas em escritórios e com a utilização de gravador, e outras ocorreram em ambientes próprios das instalações das empresas, como: chão de fábrica, laboratório de $\mathrm{P} \& \mathrm{D}$, depósito de matériaprima, entre outros. No total foram 22 entrevistas -distribuídas nas três empresas - que ocorreram ao longo de 2015. Intencionalmente foram escolhidos diretores e gerentes que estavam ligados aos processos de inovação e/ou sustentabilidade. A primeira entrevista sempre era realizada com o principal executivo (diretor executivo, diretor superintendente e/ou outros), na qual se explicitava a necessidade de se buscar dados com profissionais das diversas áreas da empresa, sendo que esse, na sequência, indicava os profissionais mais indicados à tarefa. $\mathrm{O}$ roteiro de entrevistas foi baseado nas categorias de análises levantadas previamente pela revisão de literatura e que convergem com as áreas apresentadas anteriormente na Figura 1. Assim, as questões foram dirigidas de forma a entender a percepção dos entrevistados sobre os quatro elementos de análise e suas respectivas categorias e que convergem para um processo de aprendizado organizacional para inovação ambiental.

Após a realização das entrevistas, elas foram transcritas, gerando um volume de 110 páginas e, em seguida, recorreu-se à técnica de análise de conteúdo, por meio de apoio do software N-Vivo, agrupando-se os elementos de análise e seus indicadores, conforme apresentado na próxima seção.

\section{Apresentação e Discussão dos Resultados}

A empresa Alpha está situada no Brasil e é pioneira no mercado latino-americano do segmento de rótulos adesivos, importante insumo de produção utilizado no mercado de embalagens, principalmente por empresas dos segmentos de cosméticos, alimentos, bebidas e farmacêuticos. O projeto de inovação ambiental investigado nessa empresa é o que gira em torno do liner em BOPP (polipropileno biorientado), uma importante parte da estrutura do rótulo adesivo. No entanto, no mercado brasileiro ainda predomina a utilização do liner em papel, que é ambientalmente nocivo por apresentar propriedades que dificultam sua reciclagem. 
A empresa Beta tem sua sede nos Estados Unidos, mas está presente em 23 países, inclusive no Brasil, e atua na venda de serviços de coleta/reprocessamento de resíduos de difícil reciclabilidade, que apresentam desafios maiores para seu reaproveitamento na cadeia produtiva. Esses resíduos teriam como destino aterros sanitários, lixões a céu aberto, onde poderiam ou não ser incinerados. A inovação da empresa, portanto, reside na reintrodução desses resíduos na cadeia produtiva, além de utilizá-los para a fabricação de diversos produtos, como pallets plásticos, bolsas escolares, vasos, entre outros.

A empresa Gama, por sua vez, é líder com 13\% do mercado brasileiro de energia elétrica, estando presente em oito Estados, com uma base de 7,4 milhões de clientes residenciais e corporativos. No campo de geração de energia, esta organização prioriza, em seu planejamento estratégico, a migração da utilização de energias convencionais para renováveis e, segundo seu relatório de sustentabilidade, ela é a maior geradora do Brasil a partir dessas fontes, apesar de ainda operar também com fontes sujas, como as termoelétricas. Em seu portfólio de produtos inovadores, destacam-se projetos de energia eólica, energia à base de biomassa da cana-de-açúcar, energia fotovoltaica e energia de pequenas centrais hidrelétricas. Uma vez apresentadas as empresas, serão explorados os enfoques (elementos de análise) e suas categorias, tendo como base a Figura 1.

\section{Enfoque cognitivo}

Este elemento de análise ilustra a forma como os indivíduos, os grupos de trabalho e a organização constroem e capturam o conhecimento, que é formado pelas categorias: memórias e educação ambiental.

Com relação à categoria memórias, apresenta-se a Tabela 5, com as evidências:

Tabela 5

\section{Evidências da Categoria Memórias (Subcategorias)}

\begin{tabular}{|c|c|c|c|}
\hline Subcategorias & Alpha & Beta & Gama \\
\hline $\begin{array}{l}\text { Aprendizagem } \\
\text { individual e } \\
\text { grupal }\end{array}$ & $\begin{array}{l}\text { Tanto a aprendizagem } \\
\text { individual quanto a grupal são } \\
\text { prejudicadas em função do } \\
\text { comportamento centralizador } \\
\text { do empresário que domina } \\
\text { todas as decisões estratégicas } \\
\text { e táticas. No mais, não há } \\
\text { preocupação por parte da } \\
\text { empresa em promover } \\
\text { aprendizagem no que se } \\
\text { refere às questões ambientais. }\end{array}$ & $\begin{array}{l}\text { O empresário frustra as } \\
\text { expectativas dos gerentes por } \\
\text { meio de centralização em } \\
\text { suas decisões, de forma que } \\
\text { algumas inovações esperadas } \\
\text { por esses profissionais não se } \\
\text { realizam, não havendo um } \\
\text { ambiente que propicie a } \\
\text { aprendizagem ambiental. } \\
\text { Todo corpo de conhecimento } \\
\text { dos funcionários é trazido de } \\
\text { suas próprias experiências } \\
\text { pregressas. }\end{array}$ & $\begin{array}{l}\text { O relacionamento entre } \\
\text { diretoria e gerentes e entre } \\
\text { esses e seus subordinados } \\
\text { ocorrem por meios de } \\
\text { conversas entre os times, } \\
\text { em que se privilegia o } \\
\text { diálogo e o alinhamento de } \\
\text { opiniões divergentes. }\end{array}$ \\
\hline $\begin{array}{l}\text { Sistema de } \\
\text { crenças }\end{array}$ & $\begin{array}{l}\text { A empresa possui declarações } \\
\text { de missão/visão que trazem a } \\
\text { inovação no centro de suas } \\
\text { atividades, contudo, sem se } \\
\text { referir a processos de } \\
\text { sustentabilidade. }\end{array}$ & $\begin{array}{l}\text { A empresa não possui } \\
\text { nenhuma declaração de } \\
\text { missão/visão. No entanto, são } \\
\text { disseminadas a inovação e a } \\
\text { sustentabilidade como } \\
\text { decorrentes do seu modelo de } \\
\text { negócios. }\end{array}$ & $\begin{array}{l}\text { A empresa possui } \\
\text { declarações de missão/visão } \\
\text { que retratam de forma clara } \\
\text { a orientação para a inovação } \\
\text { e sustentabilidade. }\end{array}$ \\
\hline $\begin{array}{l}\text { Sistema de metas } \\
\text { e recompensas }\end{array}$ & $\begin{array}{l}\text { A empresa não possui } \\
\text { nenhum sistema de metas e } \\
\text { recompensas sobre resultados } \\
\text { alcançados. }\end{array}$ & $\begin{array}{l}\text { A empresa não possui } \\
\text { nenhum sistema de metas e } \\
\text { recompensas sobre resultados } \\
\text { alcançados. }\end{array}$ & $\begin{array}{l}\text { A empresa possui um } \\
\text { sistema de reconhecimento } \\
\text { por metas alcançadas sob a } \\
\text { forma de bônus financeiros. }\end{array}$ \\
\hline
\end{tabular}

Nota. Elaborada pelos autores. 
Observa-se, na Tabela 5, que em Gama há evidências de um ambiente que promove a aprendizagem em nível individual e coletivo, favorecendo, consequentemente, a construção de memórias, o que não se dá em Alpha e Beta, uma vez que o comportamento centralizador dos empresários não promove esse tipo de desenvolvimento. Situação como essa já foi comentada por Cheng et al. (2014), em que o comportamento centralizador do empresário limita o desenvolvimento de ambientes de inovação ambiental.

Outro ponto observado e considerado importante no processo de formação de memórias diz respeito aos aspectos motivacionais. Esse pode ser conseguido por um sistema de metas e recompensas, no qual, para Bandura (1977), o indivíduo pode acomodar sua ação, ampliando ou comprimindo-a de acordo com seus interesses. No caso de Alpha e Beta, não foi identificado nenhum programa que estimule seus colaboradores a avançar e promover melhorias no processo de ampliação das atividades de inovação ambiental. Já no caso de Gama, há um programa de metas com seu alcance atrelado a programas de bônus anuais, o que estimula os funcionários a realizarem as ações previstas no planejamento. Sem dúvida, haveria a necessidade de se contemplar essas ações como desdobramentos da própria ação estratégica da organização (Bossle et al., 2016; Brasil, Abreu, Silva, \& Leocádio, 2016; Cheng, Yang, \& Sheu, 2014; De Marchi, 2012).

Em relação às normas vigentes, bem como às declarações de missão/visão, Gama é a única empresa que as apresenta formalmente, incluindo os temas inovação e sustentabilidade. Infere-se que a ausência de declaração da missão em Beta e a não inclusão das variáveis inovação e sustentabilidade na declaração de Alpha contribuem para gerar prejuízos para o sistema de aprendizagem como um todo, pois se deixa de alimentar a história da organização com essas prerrogativas e rotinas que potencialmente modificariam seu rumo (Castañeda, 2015; Jacobi et al., 2016; Nelson \& Winter, 1982). Em relação à aprendizagem individual nos moldes de Argyrys e Schön (1978), notou-se significativa importância para a bagagem que indivíduos trazem no que concerna à educação ambiental ou experiência pregressa em termos ambientais, traduzindo-se essas experiências como um conhecimento com potencial de disseminar ambientes de aprendizagem organizacional para a inovação ambiental, conforme observado em Beta e em Gama.

Com relação à educação ambiental, segunda categoria do elemento de análise Enfoque Cognitivo, foram contemplados, nas entrevistas, os processos formais que as empresas adotam para a disseminação de valores e conhecimentos que encorajem os funcionários, a direção e a cadeia de fornecedores a adotarem ações que tenham por objetivo a diminuição e/ou mitigação dos impactos ambientais. A Tabela 6, traz uma síntese do que foi levantado durante a pesquisa de campo.

Tabela 6

\section{Evidências da Categoria Educação Ambiental}

\begin{tabular}{|c|c|c|c|}
\hline Categoria & Alpha & Beta & Gama \\
\hline $\begin{array}{l}\text { Educação } \\
\text { Ambiental }\end{array}$ & $\begin{array}{l}\text { Não é trabalhada a educação } \\
\text { ambiental de forma a provocar } \\
\text { um pensamento } \\
\text { crítico/reflexivo. Apenas são } \\
\text { transferidos treinamentos para } \\
\text { responder às questões de } \\
\text { normatização, como os da } \\
\text { série ISO } 14000 \text { ou outros } \\
\text { decorrentes de regulação } \\
\text { imposta aos seus clientes do } \\
\text { segmento de óleos } \\
\text { lubrificantes. }\end{array}$ & $\begin{array}{l}\text { Não existe um processo } \\
\text { formal de educação ambiental. } \\
\text { Parte-se da premissa que os } \\
\text { funcionários devem adentrar } \\
\text { na organização prontos em } \\
\text { termos de educação ambiental. }\end{array}$ & $\begin{array}{l}\text { Apesar de haver um processo } \\
\text { formal de educação ambiental } \\
\text { por meio de uma ferramenta } \\
\text { de } e \text {-learning, os temas } \\
\text { trabalhados não promovem a } \\
\text { ampliação de um pensamento } \\
\text { crítico e reflexivo por parte } \\
\text { dos funcionários. }\end{array}$ \\
\hline
\end{tabular}

Nota. Elaborada pelos autores. 
Verifica-se que, em Beta, não há qualquer iniciativa para se avançar no processo de educação na organização, transferindo toda a responsabilidade aos seus próprios colaboradores. Já os resultados em Alpha e Gama reforçam os argumentos de Demajorovic (2003) de que, em muitas empresas, quando a formação em educação ambiental existe, ela se restringe a treinamentos pontuais, como preparação para auditorias dos sistemas de gestão, em detrimento de treinamentos mais amplos abrangendo temas como: mudança climática, perda de biodiversidade, poluição, produção de energia com uso de carbono, pressão sobre a água e sobre alimentos, bem como impactos ambientais e econômicos (conforme defendido por Coleman, 2013).

Reside, assim, conforme enuncia Fenwick (2007), o desafio de que empresas revisitem seus programas de treinamento e educação corporativa para a sustentabilidade, envolvendo a gerência e a base da organização. Em contraposição, observou-se que, mesmo não havendo um processo formal de educação ambiental em Beta, a formação pregressa dos indivíduos compensa essa lacuna. Isso porque esses profissionais conseguem disseminar sua bagagem de experiências passadas para o restante da organização, interferindo e modificando o rumo da operação quando necessário.

\section{Enfoque de lideranças}

Este elemento de análise retrata a importância do papel desempenhado pelos empreendedores ou altos executivos e os gerentes das organizações, que por sua liderança favorecem o processo de aprendizado que resulte em inovação ambiental. Em relação ao papel exercido pelo empreendedor e a fim de facilitar a análise de dados, essa categoria foi dividida em subcategorias, conforme apresentado pela Tabela 7:

Tabela 7

Evidências da Categoria Empreendedor

\begin{tabular}{|c|c|c|c|}
\hline Subcategorias & Alpha & Beta & Gama \\
\hline $\begin{array}{l}\text { História do } \\
\text { indivíduo }\end{array}$ & $\begin{array}{l}\text { Formação acadêmica em } \\
\text { nível de graduação na área de } \\
\text { engenharias e pós-graduação } \\
\text { em negócios, cursada em } \\
\text { universidades norte- } \\
\text { americanas. Possui grande } \\
\text { interesse em atividades de } \\
\text { invenção. }\end{array}$ & $\begin{array}{l}\text { Ingressante universitário da } \\
\text { Universidade de Princeton, } \\
\text { onde iniciou as atividades de } \\
\text { sua empresa por meio de uma } \\
\text { competição de inovação } \\
\text { desta universidade. Em } \\
\text { seguida, iniciou seus } \\
\text { negócios ampliando a } \\
\text { atividade para } 23 \text { países. }\end{array}$ & $\begin{array}{l}\text { O principal executivo da área } \\
\text { de sustentabilidade possui } \\
\text { formação acadêmica na área } \\
\text { ambiental, com } \\
\text { complementação em nível de } \\
\text { mestrado e doutorado. }\end{array}$ \\
\hline $\begin{array}{l}\text { Rotinas de } \\
\text { trabalho }\end{array}$ & $\begin{array}{l}\text { Procura canalizar e } \\
\text { centralizar todas as } \\
\text { atividades inovativas da } \\
\text { empresa, de forma que todas } \\
\text { as decisões necessitam de sua } \\
\text { chancela. }\end{array}$ & $\begin{array}{l}\text { Centraliza as decisões de sua } \\
\text { empresa, não apoiando, por } \\
\text { exemplo, a incorporação das } \\
\text { cooperativas de catadores de } \\
\text { lixo no Brasil como um } \\
\text { importante elo parceiro para } \\
\text { sua empresa. }\end{array}$ & $\begin{array}{l}\text { Atua de forma transversal por } \\
\text { todas as diretorias da } \\
\text { empresa, o que é conseguido } \\
\text { por meio de um processo de } \\
\text { planejamento estratégico. } \\
\text { Dessa forma, as questões } \\
\text { ambientais são consideradas } \\
\text { prioritárias pela empresa. }\end{array}$ \\
\hline
\end{tabular}

Nota. Elaborada pelos autores.

Cabe ressaltar que todos os empreendedores apresentaram formação educacional em instituições renomadas e declararam um grande interesse pela relação das questões ambientais com os negócios.

No entanto, verificou-se que, nas empresas de médio porte como Alpha e Beta, esses empreendedores dão pouco espaço ao diálogo, prejudicando o feedback, pois se apresentam inflexíveis quanto às sugestões de seus gerentes. Dessa forma, deriva dessa situação uma desintegração entre os níveis organizacionais (estratégico/tático/operacional), gerando ruptura no processo de aprendizagem 
individual (Argyris \& Schön, 1978; Cangelosi \& Dill, 1965; Walsh \& Ungson, 1991). No caso de Gama, há uma valorização das trocas de informações entre os gerentes e seus subordinados na resolução de problemas, ligados ou não à agenda ambiental.

Em relação à categoria Gerente, a Tabela 8 , traz as principais evidências:

Tabela 8

Evidências da Categoria Gerente

\begin{tabular}{|c|c|c|c|}
\hline Categoria & Alpha & Beta & Gama \\
\hline Gerente & $\begin{array}{l}\text { Não atuam de forma dinâmica } \\
\text { com seus times no que tange a } \\
\text { processos de inovação } \\
\text { ambiental, não promovendo, } \\
\text { portanto, esse tipo de inovação. } \\
\text { Suas ações são reativas, } \\
\text { girando em torno do } \\
\text { direcionamento fornecido pelo } \\
\text { empreendedor. }\end{array}$ & $\begin{array}{l}\text { Atuam de forma dinâmica com } \\
\text { os demais membros da cadeia } \\
\text { produtiva, promovendo a troca } \\
\text { de experiências e } \\
\text { disseminando, assim, } \\
\text { processos de aprendizagem. } \\
\text { Por meio de sua atuação, } \\
\text { consegue minimizar a } \\
\text { centralização exercida pelo } \\
\text { empreendedor. }\end{array}$ & $\begin{array}{l}\text { Atuam de forma dinâmica com } \\
\text { seus grupos e subordinados, } \\
\text { promovendo um ambiente de } \\
\text { diálogo e interação. No } \\
\text { entanto, sua atuação sofre } \\
\text { prejuízos à medida que não } \\
\text { trabalham as questões } \\
\text { ambientais de forma a } \\
\text { promover reflexão e } \\
\text { criticidade, o que é decorrente } \\
\text { de uma educação ambiental } \\
\text { frágil. }\end{array}$ \\
\hline
\end{tabular}

Nota. Elaborada pelos autores.

No caso de Alpha, há evidências de que a pouca influência desse indicador se deve à barreira criada pela centralização promovida pelo empreendedor, de forma que os gerentes não possuem flexibilidade ou autonomia para propor melhorias e avanços no sistema de inovação. Soma-se a isso o baixo nível de educação ambiental recebido no exercício da função ou em sua formação educacional pregressa.

No caso de Gama, os gerentes procuram promover o diálogo com seus times. No entanto, essa interação sofre prejuízos quando esbarra no limite imposto pela fragilidade com que são abordados os temas ambientais. Consequentemente, isso gera falhas no processo de transferi-las para os níveis hierarquicamente inferiores (Espinosa \& Porter, 2011; Jacobi et al., 2016; Jacomossi, Morano, \& Barrichello, 2014; Zhang et al., 2013). No caso de Beta, apesar de algumas limitações impostas pelo diretor-presidente no que se refere ao trabalho com as cooperativas de catadores de lixo reciclável (Tabela 8), essa barreira não interfere no papel dos gerentes em disseminar ambientes de aprendizagem, uma vez que eles atuam de forma dinâmica por toda a cadeia produtiva divulgando e treinando as equipes quanto às práticas ambientais corretas. Constatou-se que isso se deve à própria formação educacional pregressa para a sustentabilidade, que reforça a prática desses gerentes, direcionando-os para desenvolverem ações nessa temática.

\section{Enfoque funcional}

Este elemento de análise visa a investigar aspectos concernentes às rotinas implantadas nas organizações, como os sistemas de gerenciamento ambientais e a existência de departamentos de P\&D, focando este último a interação entre clientes e fornecedores, conforme observa-se na Tabela 9: 
Tabela 9

\section{Evidências da Categoria P\&D em Redes}

\begin{tabular}{|c|c|c|c|}
\hline Categoria & Alpha & Beta & Gama \\
\hline P\&D em Redes & $\begin{array}{l}\text { Trabalha em parceria com } \\
\text { universidades e fornecedores. } \\
\text { O papel da universidade é } \\
\text { importante para esta empresa, } \\
\text { pois possibilita que se } \\
\text { acessem financiamentos para } \\
\text { inovação. No entanto, os } \\
\text { funcionários de Alpha não } \\
\text { enxergam aplicabilidade no } \\
\text { discurso e atuação proferida } \\
\text { pelas universidades, devido } \\
\text { muitas vezes, à dificuldade de } \\
\text { se implantar os projetos que } \\
\text { estão no escopo de pesquisa } \\
\text { das universidades. }\end{array}$ & $\begin{array}{l}\text { Seu departamento de P\&D se } \\
\text { situa na matriz, nos Estados } \\
\text { Unidos, no qual são } \\
\text { desenvolvidas soluções de } \\
\text { forma isolada, sem interação } \\
\text { dos seus funcionários com as } \\
\text { universidades. Isso se deve a } \\
\text { um direcionamento do } \\
\text { empreendedor, que enxerga a } \\
\text { universidade como uma } \\
\text { instituição que não privilegia } \\
\text { as atividades práticas que } \\
\text { poderiam ser aplicadas por } \\
\text { empresas. } \\
\text { A empresa enxerga como } \\
\text { potencial as parcerias que } \\
\text { desenvolve com fornecedores, } \\
\text { uma vez que, por meio dessas } \\
\text { parcerias, pode-se reduzir } \\
\text { custos e aumentar as escalas } \\
\text { de produção. }\end{array}$ & $\begin{array}{l}\text { Trabalha em parceria tanto } \\
\text { com universidades como com } \\
\text { fornecedores. Enxerga o papel } \\
\text { da universidade como } \\
\text { importante, no entanto, } \\
\text { reconhecem um discurso } \\
\text { desconexo da universidade no } \\
\text { que se refere a se alinhar com } \\
\text { os interesses da sociedade. Já } \\
\text { em relação aos fornecedores, } \\
\text { reconhecem sua importância } \\
\text { para o desenvolvimento de } \\
\text { soluções tecnológicas, } \\
\text { principalmente para se reduzir } \\
\text { custos e ampliar as escalas de } \\
\text { produção. }\end{array}$ \\
\hline
\end{tabular}

Nota. Elaborada pelos autores.

Todas as três empresas trabalham com P\&D de forma colaborativa com fornecedores e, no caso de Alpha e Gama, também com universidades. Apesar de ter havido alguns projetos em parceria com o meio acadêmico que se desdobraram em inovações ambientais, as entrevistas revelaram um distanciamento de interesses entre esses dois atores, sobretudo na opinião dos gestores das empresas, pelas dificuldades de aplicação do conhecimento gerado nas instituições de ensino, além do desalinhamento de suas agendas com a agenda corporativa, fragilizando os resultados da inovação ambiental (Dlouhá, Barton, \& Janousková, 2013; Fenwick, 2007; Nogueira \& Odelius, 2015; Prugsamatz, 2010; Santos \& Sampaio, 2016; Styles, Schoenberger, \& Galvez-Martos, 2012).

Ressalta-se, portanto, o desafio de promover o realinhamento de diálogo entre esses dois atores. Também na análise desta categoria revelou-se o desafio de se criar tecnologias para a ampliação de economias de escala (Gavronski, Klassen, Vachon, \& Nascimento, 2012; Köhler et al., 2013), tanto para Alpha no caso do liner, quanto para Beta no caso dos materiais que possuem dificuldade tecnológica para reciclagem, o que gera altos custos de processamento.

Em relação à Gama, essa situação se revela na dificuldade em conseguirem implantar, por exemplo, projetos para geração de energia por intermédio de resíduos industriais. Assim, desenvolver, de forma colaborativa e em redes, tecnologias que possibilitem a promoção de economias de escala, possui o potencial de ampliar os processos de aprendizagem para a inovação ambiental.

A segunda categoria presente no elemento de análise Enfoque Funcional se refere aos processos de controles ambientais, representados por Gestão Ambiental, conforme observa-se na Tabela 10: 
Tabela 10

\section{Evidências da Categoria Gestão Ambiental}

\begin{tabular}{|c|c|c|c|}
\hline Categoria & Alpha & Beta & Gama \\
\hline Gestão Ambiental & $\begin{array}{l}\text { A empresa possui um } \\
\text { sistema de gestão ambiental } \\
\text { estruturado para atender às } \\
\text { normas da Política Nacional } \\
\text { de Resíduos Sólidos, que } \\
\text { estabelece que alguns setores } \\
\text { da economia tenham uma } \\
\text { política de descarte correto } \\
\text { de resíduos industriais. A } \\
\text { empresa mantém suas } \\
\text { operações dentro das } \\
\text { especificações solicitadas } \\
\text { pela norma, a fim de não } \\
\text { ficar vulnerável a multas e } \\
\text { outras implicações. }\end{array}$ & $\begin{array}{l}\text { A empresa não possui um } \\
\text { sistema de gestão ambiental } \\
\text { integrado. No entanto, como } \\
\text { a empresa é uma prestadora } \\
\text { de serviço para coleta e } \\
\text { descarte de resíduos } \\
\text { industriais de difícil } \\
\text { reciclabilidade, ela mantém } \\
\text { todos seus fornecedores de } \\
\text { serviços vistoriados de } \\
\text { forma a assegurar que esses } \\
\text { cumpram padrões mínimos } \\
\text { de gerenciamento ambiental. }\end{array}$ & $\begin{array}{l}\text { A empresa não possui um } \\
\text { sistema oficial de gestão } \\
\text { ambiental integrada pela } \\
\text { norma ISO, contudo, } \\
\text { obedece fielmente aos } \\
\text { princípios operacionais do } \\
\text { sistema de gestão ambiental, } \\
\text { com base nos Princípio do } \\
\text { Equador. Além disso, a } \\
\text { empresa atua na fiscalização } \\
\text { das operações ambientais de } \\
\text { seus principais fornecedores. }\end{array}$ \\
\hline
\end{tabular}

Nota. Elaborada pelos autores.

Todas as empresas apresentaram influência significativa nesse indicador, no entanto, Alpha e Gama se sobressaem, por manterem sistemas formais e estruturados de gestão ambiental. Já Beta, embora não mantenha um sistema formal, realiza acompanhamentos rotineiros nos programas de seus entrepostos, gerando resultados significativos.

\section{Enfoque externo}

O quarto e último elemento de análise objetiva conferir a importância dos aspectos externos, aqui representados pelas categorias regulação e usuários de produtos, conforme descrito na Tabela 11:

Tabela 11

Evidências dos Elementos do Enfoque Externo

\begin{tabular}{|c|c|c|c|}
\hline Categoria & Alpha & Beta & Gama \\
\hline Regulação & $\begin{array}{l}\text { Não é diretamente } \\
\text { regulada, mas alguns de } \\
\text { seus clientes o são pela } \\
\text { legislação relativa a } \\
\text { resíduos sólidos, o que } \\
\text { direciona as ações desta } \\
\text { empresa para atender a } \\
\text { esta normatização. }\end{array}$ & $\begin{array}{l}\text { Seus clientes são na } \\
\text { maioria multinacionais, que } \\
\text { antecipam suas ações a fim } \\
\text { de atender às } \\
\text { normatizações futuras, } \\
\text { embora a empresa, em } \\
\text { específico, não receba } \\
\text { nenhuma restrição relativa } \\
\text { à legislação. }\end{array}$ & $\begin{array}{l}\text { A empresa é diretamente } \\
\text { regulada pela Agência } \\
\text { Nacional de Energia Elétrica } \\
\text { que impõe uma série de } \\
\text { restrições e de políticas que } \\
\text { devem ser seguidas no que } \\
\text { tange às atividades e } \\
\text { investimentos em inovação, } \\
\text { por exemplo. }\end{array}$ \\
\hline Usuários de Produtos & $\begin{array}{l}\text { O produto fruto da } \\
\text { inovação ambiental, o } \\
\text { liner em BOPP, não é } \\
\text { valorizado e demandado } \\
\text { pelo cliente. }\end{array}$ & $\begin{array}{l}\text { Os clientes da empresa } \\
\text { utilizam o serviço no limite } \\
\text { de suas verbas de } \\
\text { marketing. }\end{array}$ & $\begin{array}{l}\text { Os clientes valorizam as } \\
\text { fontes renováveis de energia } \\
\text { quando as taxas são } \\
\text { economicamente mais } \\
\text { viáveis do que as de fontes } \\
\text { não renováveis. }\end{array}$ \\
\hline
\end{tabular}

Nota. Elaborada pelos autores. 
A categoria regulação se mostrou extremamente relevante para promover ambientes de aprendizagem organizacional para a inovação ambiental. Mesmo para as empresas Alpha e Beta, que não são atingidas diretamente por nenhuma imposição legal, alguns de seus clientes o são, fato que impele ajustes na cadeia produtiva (Berrone, Fosfuri, \& Gelabert, 2013; De Marchi, 2012; Jacomossi et al., 2016; Marinescu et al., 2015). Dessa forma, clientes dessas empresas, no anseio de responderem às pressões regulatórias, buscam, no mercado, parceiros comerciais que estejam preparados para lidar operacionalmente com esses desafios. Um exemplo são os clientes de Alpha situados no segmento de óleos lubrificantes que, para gerenciarem as exigências da política nacional de resíduos sólidos (PNRS), contratam-na usando o produto liner em BOPP a fim de legitimar suas operações.

Já no caso de Gama, a legislação opera como uma força direta por meio da atuação de uma agência reguladora, o que por si estimula o sistema de aprendizagem. Existe, por parte da legislação, uma obrigatoriedade em se investir em inovação, e a empresa utiliza parte dessa verba para investir em projetos de inovação ambiental. Nesse caso, os avanços do marco regulatório do setor geraram uma visão de oportunidade para a organização no que tange aos investimentos nesse tipo de inovação, incluindo, em seu planejamento estratégico, a expansão das energias renováveis na sua matriz de geração.

No que se refere à categoria usuários de produtos, essa não apresentou nenhuma relevância em termos de influência sobre processos de aprendizagem organizacional para a inovação ambiental, embora a literatura (Carrillo-Hermosilla et al., 2010; Horbach, Rammer, \& Rennings, 2012; Liddle \& El-Kafafi, 2010; Ramus \& Steger, 2000) enalteça a força dessa dimensão como indutora deste processo.

A barreira encontrada para as três empresas se apresentou basicamente na esfera econômica, uma vez que produtos decorrentes de inovação ambiental ainda não possuem escala de produção suficiente a ponto de se obter um preço mais competitivo que os produtos tradicionais, sendo este ainda um aspecto importante na análise dos consumidores, sejam eles finais ou intermediários. Para Alpha, a não aceitação dos clientes se deve à preferência do liner em papel, em detrimento do liner em BOPP. Desconsiderando o melhor desempenho ambiental do liner de BOPP em função de reciclabilidade, a maior parte dos usuários pautam suas decisões de compra exclusivamente em função do custo menor do liner tradicional, além do fato de que os clientes não gostariam de ficar dependentes de um único fornecedor, que poderia regular livremente o sistema de preços. Já Beta, por não possuir tecnologias desenvolvidas que possibilitem um baixo custo de operação para os projetos de coleta de resíduo patrocinado, afasta os potenciais clientes que teriam a intenção de implantar tais projetos. Para Gama, o limite se apresentou justamente no preço da tarifa da energia elétrica, que seguiria um rito de decisão pelo consumidor, em função do menor preço e não pelo benefício ambiental gerado.

A fim de visualizar os resultados em função do comportamento das variáveis analisadas em cada uma das empresas estudadas, formulou-se a Tabela 12, classificando-se a intensidade da influência dessas variáveis sobre o processo de aprendizagem para a inovação ambiental.

Tabela 12

Comparação Sintética dos Efeitos das Categorias sobre o Processo de Aprendizagem Organizacional para a Inovação Ambiental nas Empresas Estudadas

\begin{tabular}{lllll} 
& & Empesas & & \\
\hline Categorias & Indicadores & Alpha & Beta & Gama \\
\hline \multirow{2}{*}{ Enfoque Cognitivo } & Memórias & Baixa & Média & Alta \\
& Educação Ambiental & Pouca & Pouca & Média \\
\hline \multirow{2}{*}{ Enfoque de Lideranças } & Empreendedor & Alta & Alta & Alta \\
& Gerente & Pouca & Alta & Média \\
\hline
\end{tabular}


Tabela 12 (continuação)

\begin{tabular}{lll|l|l}
\cline { 3 - 5 } Categorias & Indicadores & Alpha & Beta & Gama \\
\hline \multirow{2}{*}{ Enfoque Funcional } & P\&D em Redes & Alta & Média & Alta \\
\cline { 2 - 5 } & Gestão Ambiental & Alta & Média & Alta \\
\hline \multirow{2}{*}{ Enfoque Externo } & Regulação & Alta & Alta & Alta \\
\cline { 2 - 5 } & Usuários de Produtos & Pouca & Pouca & Pouca \\
\hline
\end{tabular}

Nota. A intensidade de influência foi definida de acordo com as evidências encontradas em cada um dos indicadores. Elaborada pelos autores.

Os resultados dos três casos indicam que as categorias regulação e o papel do empreendedor apresentam maior potencial como catalizadores do processo de aprendizagem organizacional para a inovação ambiental. Já a categoria usuário dos produtos não apresenta nenhuma influência para induzir esse tipo de aprendizagem nas empresas. Nas demais categorias não foi possível identificar similitudes nas empresas analisadas.

\section{Conclusões}

Ao se percorrer a temática da inovação ambiental, percebe-se que os estudos se dedicam a apontar os determinantes desse tipo de inovação, sem necessariamente associá-los a processos de aprendizagem organizacional e/ou de aprendizagem para a sustentabilidade, tendo sido esse, portanto, o intento desta pesquisa. Com base na revisão da literatura e atendendo à primeira pergunta colocada, foi proposto um modelo conceitual de análise em torno de processos de aprendizagem organizacional para a inovação ambiental, resultando em quatro elementos de análise e suas respectivas categorias: Externo (regulação; usuários de produtos); Lideranças (empreendedor; gerente); Cognitivo (memórias; educação); e Funcional (P\&D em redes; gestão ambiental).

Com exceção da categoria usuários de produtos, todas as demais foram identificadas na empresa Gama como influenciadoras de processos de aprendizagem organizacional que culminam em inovações ambientais. Já nas empresas Alpha e Beta houve comportamentos diferentes tanto no que se refere à própria identificação das variáveis bem como na intensidade com que essas variáveis influenciam as atividades de inovação ambiental.

Em relação à segunda questão e considerando-se o modelo proposto nas três empresas, as categorias regulação e empreendedor apresentaram maior influência em comparação com as demais. No que tange à categoria regulação, ela exerce forte influência no processo de aprendizagem organizacional para a inovação ambiental (Barla, 2007; Berrone et al., 2013; Ceschin, 2013; Jacomossi et al., 2016; Marinescu et al., 2015), tanto em setores que são diretamente influenciados por essa categoria, como observado em Gama, bem como nos que não o são, como observado em Alpha e Beta. Para essas duas organizações, a possibilidade de haver restrições legais no futuro gera movimentos antecipados para adequar suas operações às de boas práticas ambientais.

A categoria empreendedor se mostrou extremamente relevante em relação ao processo de aprendizagem organizacional para a inovação ambiental nas três empresas (Faustenhammer \& Gössler, 2011). No entanto, como se observou em Alpha e Beta, ambas empresas de médio porte, o empreendedor tende a centralizar suas tomadas de decisões, o que pode interromper o fluxo de aprendizagem (Kuntz \& Gomes, 2012).

Por outro lado, esta situação pode ser revertida quando há uma atuação forte e direta por parte do gerente, uma vez que ele consegue compensar o perfil autoritário e centralizador do empreendedor por 
meio de sua atuação com os demais stakeholders. Em grande medida, essa situação ocorre quando esses profissionais têm formação educacional diferenciada em termos ambientais, o que possibilita que disseminem informações pelo restante da cadeia produtiva, atenuando, portanto, o papel centralizador do empreendedor.

Vale frisar a importância da categoria memórias, representada pelas subcategorias aprendizagem individual e grupal, além do sistema de metas, recompensas e crenças da organização, também reconhecido como importante instrumento para a disseminação de ambientes de aprendizagem. A incorporação dos valores ambientais nas declarações de missão/visão, além das experiências acumuladas em torno da temática ambiental (Jacobi et al., 2016), alimenta a história da organização na direção de outras inovações sob a mesma dimensão (Nelson \& Winter, 1982), reforçando o processo de transferência da memória organizacional, conforme postula Becker (2010).

Com relação ao enfoque funcional presente na proposição do modelo, esse nível foi representado pelas categorias P\&D em redes e gestão ambiental. O primeiro se revelou de extrema importância para a emergência da criação de tecnologias que possibilitem a ampliação de economias de escala (Gavronski et al., 2012; Köhler et al., 2013), que é uma importante lacuna que limita a extensão dos processos de aprendizagem para a inovação ambiental, já que os custos econômicos envolvidos nos projetos representam uma forte barreira a ser suplantada.

Por outro lado, revelou-se, nesta pesquisa, uma fragilidade na relação empresas - universidades, representada pela insatisfação dos entrevistados [empresas] em relação à interação com as universidades, fato consubstanciado pelo distanciamento existente entre as demandas das empresas e os interesses de pesquisa das universidades.

Já a categoria gestão ambiental também se apresentou como significativa em relação ao processo de aprendizagem para a inovação ambiental nas três empresas. Mesmo não havendo, por exemplo, um processo formal em Beta, a companhia atua por meio de práticas concernentes à gestão integrada, processo que, para Stoughton e Ludema (2012), representa um modelo que reforça a atitude dos indivíduos em imergir nas questões ambientais da organização.

Concluso, o modelo proposto no estudo reforçou o papel da regulação e do empreendedor, mas não encontrou evidências para a categoria usuário de produtos, comumente associada a fator indutor de aprendizagem e inovação. Além disso, as demais categorias que aparecem como indutores em um ou dois casos mostram a importância de se avançar os estudos, ampliando os casos ou desenvolvendo um estudo quantitativo e confirmatório para as categorias identificadas e propostas nesta pesquisa, relacionando aprendizagem e o processo de inovação ambiental.

Ainda que a estratégia de pesquisa escolhida tenha privilegiado o estudo multicaso, um limite do trabalho apresentado é a impossibilidade de generalização dos resultados, uma vez que a pesquisa contempla apenas três empresas. Além disso, há diferenças entre elas no que se refere à origem do capital, porte e mercados de atuação, o que por si só gera algumas disparidades. Por outro lado, sugerese que pesquisas futuras possam se apropriar do modelo conceitual aqui proposto, a fim de se desenvolver uma escala e se averiguar o fenômeno da aprendizagem organizacional para a inovação ambiental por uma lente quantitativa, podendo-se, sim, a partir deste momento, testar e confirmar hipóteses.

\section{Referências}

Ângelo, F. D., Jabbour, C. J. C., \& Galina, S. V. R. (2011). Inovação ambiental: das imprecisões conceituais a uma definição comum no âmbito da gestão ambiental proativa. Gestão da Produção, Operações e Sistemas, 6(4), 143-155. 
Ângelo, F. D., Jabbour, C. J. C., \& Galina, S. V. R. (2012). Environmental innovation: In search of a meaning. World Journal of Entrepreneurship, Management and Sustainable Development, 8(2/3), 113-121. http://dx.doi.org/10.1108/20425961211247734

Antonello, C. S., \& Godoy, A. S. (2010). A encruzilhada da aprendizagem organizacional: Uma visão multiparadigmática. Revista de Administração Contemporânea, 14(2), 310-332. Recuperado de http://www.scielo.br/pdf/rac/v14n2/v14n2a08.pdf. 65552010000200008

Argote, L., \& Miron-Spektor, E. (2011). Organizational learning: From experience to knowledge. Organization Science, 22(5), 1123-1137. http://dx.doi.org/10.1287/orsc.1100.0621

Argyris, C., \& Schön, D. (1978). Organizational learning: A theory of action perspective. Reading, Massachusetts: Addison-Wesley.

Argyris, C., \& Schön, D. (1991). Teaching smart people how to learn. Harvard Business Review, 69(3), 99-109.

Ayres, R. M. S. de M., \& Popadiuk, S. (2016). Knowledge transfer, learning and organization capabilities in an interorganizational software project. Organizações \& Sociedade, 23(79), 553570. http://dx.doi.org/10.1590/1984-9230792

Bandura, A. (1977). Social learning theory. Englewood Cliffs: Prentice-Hall.

Banerjee, S. B. (2003). Who sustains whose development? Sustainable development and the reinvention $\begin{array}{llll}\text { of } & \text { nature. } & \text { Organization }\end{array}$ http://dx.doi.org/10.1177/0170840603024001341

Barla, P. (2007). ISO 14001: Certification and environmental performance in Quebec's pulp and paper industry. Journal of Environmental Economics and Management, 53(3), 291-306. http://dx.doi.org/10.1016/j.jeem.2006.10.004

Becker, K. (2010). Facilitating unlearning during implementation of new technology. Journal of Organizational Change, 23(3) 251-268. http://dx.doi.org/10.1108/09534811011049590

Beise, M., \& Rennings, K. (2005). Lead markets and regulation: A framework for analyzing the international diffusion of environmental innovations. Ecological Economics, 52(1), 5-17. http://dx.doi.org/10.1016/j.ecolecon.2004.06.007

Berger, P. L., \& Luckmann, T. (1985). A construção social da realidade. Petrópolis: Vozes.

Berrone, P., Fosfuri, A, Gelabert, L., \& Gomez-Mejia, L. R. (2013). Necessity as the mother of 'green' inventions: Institutional pressures and environmental innovations. Strategic Management Journal, 34(8), 891-909. http://dx.doi.org/10.1002/smj.2041

Bevis, K. (2011). The challenges for sustainable skills development in the UK automotive supply sector: Policy and implementation. Management Research Review, 34(1), 133-147. http://dx.doi.org/10.1108/01409171111096513

Beyene, K. T., Shi, C. S., \& Wu, W. W. (2016). The impact of innovation strategy on organizational learning and innovation. South African Journal of Industrial Engineering, 27(1), 125-136. http://dx.doi.org/10.7166/27-1-1308

Bossle, M. B., Barcellos, M. D., Vieira, L. M., \& Sauv, L. (2016). The drivers for adoption of ecoinnovation. Journal of Cleaner Production, 113(1), 861-872. http://dx.doi.org/10.1016/j.jclepro.2015.11.033 
Botes, V., Low, M., \& Chapman, J. (2014). Is accounting education sufficiently sustainable? Sustainability Accounting, Management and Policy Journal, 5(1), 95-124. http://dx.doi.org/10.1108/SAMPJ-11-2012-0041

Brasil, M. V. de O., Abreu, M. C. S. de, Silva, J. C. L., Filho, \& Leocádio, A. L. (2016). Relationship between eco-innovations and the impact on business performance: An empirical survey research on the Brazilian textile industry. Revista de Administração, 51(3), 276-287. http://dx.doi.org/10.1016/j.rausp.2016.06.003

Cangelosi, V., \& Dill, W. (1965). Organizational learning: Observations towards a theory. Administrative Science Quarterly, 10(2), 175-203. http://dx.doi.org/10.2307/2391412

Carrillo-Hermosilla, J., Del Río, P., \& Könölla, T. (2010). Diversity of eco-innovations: Reflections from selected case studies. Journal of Cleaner Production, 18(10), 1073-1083. http://dx.doi.org/10.1016/j.jclepro.2010.02.014

Castañeda, D. I. (2015). Condiciones para el aprendizaje orgaizacional. Estudios Gerenciales, 31(134), 62-67. http://dx.doi.org/10.1016/j.estger.2014.09.003

Ceschin, F. (2013). Critical factors for implementing and diffusing sustainable product-service systems: Insight from innovation studies and companies experiences. Journal of Cleaner Production, 45, 74-88. http://dx.doi.org/10.1016/j.jclepro.2012.05.034

Cheetham, G., \& Chivers, G. (1998). The reflective (and competent) practitioner: A model of professional competence which seeks to harmonise the reflective practitioner and competence based approaches. Journal of European Industrial Training, 22(7), 267-276. http://dx.doi.org/10.1108/03090599810230678

Cheng, C. C. J., Yang, C.-I., \& Sheu, C. (2014). The link between eco-innovation and business performance: A Taiwanese industry context. Journal of Cleaner Production, 64(1), 81-90. http://dx.doi.org/10.1016/j.jclepro.2013.09.050

Claro, P. B. O. (2008). Entendendo o conceito de sustentabilidade nas organizações. Revista de Administração, 43(4), 289-300. http://dx.doi.org/10.1590/S0080-21072008000400001

Coleman, G. (2013). Sustainability as a learning challenge. Journal of Management Development, 32(3), 258-267. http://dx.doi.org/10.1108/02621711311318292

Cortêss, P. L., \& Rodrigues, R. (2016). A bibliometric study on "education for sustainability". Brazilian Journal of Science and Technology, 3(8), 1-17. http://dx.doi.org/10.1186/s40552-016-0016-5

Demajorovic, J. (2003). Sociedade de risco e responsabilidade socioambiental: Perspectivas para a educação corporativa. São Paulo: Editora Senac.

De Marchi, V. (2012). Environmental innovation and R\&D cooperation: Empirical evidence from Spanish manufacturing firms. Research Policy, 41(3), 614-623. http://dx.doi.org/10.1016/j.respol.2011.10.002

Dlouhá, J., Barton, A., \& Janousková, D. (2013). Social learning indicators in sustainability-oriented regional learning networks. Journal of Cleaner Production, 49(1), 64-73. http://dx.doi.org/10.1016/j.jclepro.2012.07.023

Edwards, M. G. (2009). An integrative metatheory for organizational learning and sustainability in turbulent times. The Learning Organization, 16(3), 189-207. http://dx.doi.org/10.1108/09696470910949926

Eisenhardt, K. M. (1989). Building theories from case study research. Academy of Management Review, 14(4), 532-550. http://dx.doi.org/10.5465/AMR.1989.4308385 
El-Kafafi, S., \& Liddle, S. (2011). Innovative sustainable practices: Are they commercially viable? World Journal of Entrepreneurship, Management and Sustainable Development, 6(1/2), 19-28. http://dx.doi.org/10.1108/20425961201000002

Espinosa, A., \& Porter, T. (2011). Sustainability, complexity and learning: Insights from complex $\begin{array}{llll}\text { approaches. The Learning } & \text { Organization, }\end{array}$ http://dx.doi.org/10.1108/09696471111096000

Faustenhammer, A., \& Gössler, M. (2011). Preparing for the next crisis: What can organizations do to prepare managers for an uncertain future? Business Strategy Series, 12(2), 51-55. http://dx.doi.org/10.1108/17515631111114840

Fenwick, T. (2007). Developing organizational practices of ecological sustainability: A learning perspective. Leadership \& Organization Development Journal, 28(7), 632-645. http://dx.doi.org/10.1108/01437730710823888

Ferreira, J. F., \& Godoy, A. S. (2015). Processos de aprendizagem: Um estudo em três restaurantes de um clube étnico alemão de negócios, gastronomia e cultura. Revista de Administração Mackenzie, 16(2), 15-44. http://dx.doi.org/10.1590/1678-69712015/administracao.v16n2p15-44

Fiol, C. M., \& Lyles, M. A. (1985). Organizational learning. Academy of Management Review, 10(4), 803-813. http://dx.doi.org/10.5465/AMR.1985.4279103

Ford, J. A., Steen, J., \& Verreynne, M.-L. (2014). How environmental regulations affect innovation in the Australian oil and gas industry: Going beyond the Porter hypothesis. Journal of Cleaner Production, 84(1), 204-213. http://dx.doi.org/10.1016/j.jclepro.2013.12.062

Gavronski, I., Klassen, R. D., Vachon, S., \& Nascimento, L. F. M. do (2012). A learning and knowledge approach to sustainable operations. International Journal Production Economics, 140(1), 183192. http://dx.doi.org/10.1016/j.ijpe.2012.01.037

Giddens, A. (1991). As consequências da modernidade. São Paulo: Unesp.

Halila, F., \& Rundquist, J. (2011). The development and marketsuccess of eco-innovations. A comparative study of eco-innovations and "other" innovations in Sweden. European Journal of Innovation Management, 14(3). http://dx.doi.org/10.1108/14601061111148807

Hansen, E. G., \& Klewitz, J. (2012). The role of an SME's green strategy in public-private ecoinnovation initiatives: The case of ecoprofit. Journal of Small Business and Entrepreneurship, 25(4), 451-477. http://dx.doi.org/10.1080/08276331.2012.10593584

Horbach, J., Rammer, C., \& Rennings, K. (2012). Determinants of eco-innovations by type of environmental impacts - The role of regulatory push/pull, technology push and market pull. Ecological Economics, 78, 112-122. http://dx.doi.org/10.1016/j.ecolecon.2012.04.005

Huber, G. P. (1991). Organizational learning: The contributing processes and the literatures. Organization Science, 2(1), 88-115. http://dx.doi.org/10.1287/orsc.2.1.88

Ichijo, K., \& Nonaka, I. (2007). Knowledge creation and management: New challenges for managers. Oxford: Oxford University Press.

Jacobi, P. R., Toledo, R. F., \& Grandisoli, E. (2016). Education, sustainability and social learning. Brazilian Journal of Science and Technology, 3(1), 1-8. https://doi.org/10.1186/s40552-0160019-2

Jacomossi, R., Demajorovic, J., Santiago, A. L., \& Bernardes, R. (2016). Fatores determinantes da ecoinovação: Um estudo de caso a partir de uma indústria gráfica brasileira. Gestão \& Regionalidade, 32(94), 101-117. http://dx.doi.org/10.13037/gr.vol32n94.3134 
Jacomossi, R., Morano, R., \& Barrichelo, A. (2014). O comportamento ambiental de estudantes de graduação: Um modelo internacional de equações estruturais aplicado ao contexto brasileiro. Revista de Gestão Social e Ambiental, 8(3), 106-117. http://dx.doi.org/10.24857/rgsa.v8i3.957

Jamali, D. (2006). Insights into triple bottom line integration from a learning organization perspective. $\begin{array}{llll}\text { Business Process Management Journal, } & \text { 12(6), }\end{array}$ http://dx.doi.org/10.1108/14637150610710945

Kammerer, D. (2009). The effects of customer benefit and regulation on environmental products innovation. Empirical evidence from appliance manufactures in Germany. Ecological Economics, 68(8/9), 2285-2295. http://dx.doi.org/10.1016/j.ecolecon.2009.02.016

Klewitz, J., Zeyen, A., \& Hansen, E. G. (2012). Intermediaries driving eco-innovation in SMEs: a qualitative investigation. European Journal of Innovation Management, 15(4), 442-467. http://dx.doi.org/10.1108/14601061211272376

Köhler, J., Schade, W., Leduc, G., Wiesenthal, T., Schade, B., \& Espinoz, L. T. (2013). Leaving fossil fuels behind? An innovation system analysis of low carbon cars. Journal of Cleaner Production, 48, 176-186. http://dx.doi.org/10.1016/j.jclepro.2012.09.042

Kuntz, J. R. C., \& Gomes, J. F. S. (2012). Transformational change in organizations: A self-regulation approach. Journal of Organizational Change Management, 25(1), 143-162. http://dx.doi.org/10.1108/09534811211199637

Liddle, S., \& El-Kafafi, S. (2010). Drivers of sustainable innovation push, pull or policy. World Journal of Enterprenuership, Management and Sustainable Development, 6(4), 293-305. http://dx.doi.org/10.1108/20425961201000022

Loukas, N. A. (2012). The sustainable management vision for excellence: Implications for business education. International Journal of Quality and Service Sciences, 4(1), 61-75. http://dx.doi.org/10.1108/17566691211219733

Marinescu, C., Ciocoiu, C. N., \& Cicea, C. (2015). Drivers of eco-innovation within waste eletrical and electronic equipment field. Theoretical and Empirical Researches in Urban Management, 10(4), 5-19.

Meng, X. (2014). The role of facilities managers in sustainable practice in the UK and Ireland. Smart and Sustainable Built Environment, 3(1), 23-34. http://dx.doi.org/10.1108/SASBE-03-2013-0012

Nelson, R., \& Winter, S. (1982). An evolutionary theory of economic change. Cambridge: Belknap.

Nogueira, R. A., \& Odelius, C. C. (2015). Desafios da pesquisa em aprendizagem organizacional. Cadernos Ebape.BR, 13(1), 83-102. http://dx.doi.org/10.1590/1679-395112602

Piaget, J. (1978). A epistemologia genética: Sabedoria e ilusões da filosofia; problemas de psicologia genética. São Paulo: Abril Cultural.

Porter, M. E., \& Linde, C. van der (1995). Toward a new conception of the environmentcompetitiveness relationship. The Journal of Economic Perspectives, 9(4), 97-118. http://dx.doi.org/10.1257/jep.9.4.97

Prugsamatz, R. (2010). Factors that influence organization learning sustainability in non-profit $\begin{array}{lllll}\text { organizations. The } \quad \text { Learning } & \text { Organization, } 267 .\end{array}$ http://dx.doi.org/10.1108/09696471011034937

Quist, J., \& Tukker, A. (2013). Knowledge collaboration and learning for sustainable innovation and consumption: introduction to the ERSCP portion of this special volume. Journal of Cleaner Production, 48, 167-175. http://dx.doi.org/10.1016/j.jclepro.2013.03.051 
Ramus, C. A., \& Steger, U. (2000). The roles of supervisory support behaviours and environmental policy in employee "Ecoinitiatives" at leading-edge European companies. Academy of Management Journal, 43(4), 605-626. http://dx.doi.org/10.2307/1556357

Santolaria, M., Solà, J. O., Gasol, C. M., Morales-Pinzón, T., \& Rieradevall, J. (2012). Eco-design in innovation driven companies: perception, predictions and the main drivers of integration. The Spanish example. European Journal of Innovation Management, 15(4), 442-467. http://dx.doi.org/10.1016/j.jclepro.2011.03.009

Santos, J. L. dos, \& Sampaio, R. R. (2016). Redes sociais informais e difusão do conhecimento: Uma proposta de modelagem em um ambiente de desenvolvimento de projetos de Informal social networks and knowledge diffusion: A modeling proposal applied to a software development environment. Perpsectivas em Ciências da Informação, 21(3), 134-164. http://dx.doi.org/10.1590/1981-5344/2634

Senge, P. (1990). A quinta disciplina: arte, teoria e prática da organização. São Paulo: Best Seller.

Shu, C., Zhou, K. Z., Xiao, Y., \& Gao, S. (2016). How green management influences product innovation in China: The role of institutional benefits. Journal of Business Ethics, 133(3), 471-485. http://dx.doi.org/10.1007/s10551-014-2401-7

Siebenhüner, B., \& Arnold, M. (2007). Organizational learning to manage sustainable development. Business Strategy and the Environment, 16(5), 339-353. http://dx.doi.org/10.1002/bse.579

Soares, G. M. P. (2004). Responsabilidade social corporativa: Por uma boa causa!? RAE-eletrônica, 3(2), 1-15. Recuperado de http://www.scielo.br/pdf/raeel/v3n2/v3n2a07

Soparnot, R. (2011). The concept of organizational change capacity. Journal of Organizational Change Management, 24(5), 640-661. http://dx.doi.org/10.1108/09534811111158903

Stoughton, A. M., \& Ludema, J. (2012). The driving forces of sustainability. Journal of Organizational Change, 25(4), 501-517. http://dx.doi.org/10.1108/09534811211239191

Styles, D., Schoenberger, H., \& Galvez-Martos, J. L. (2012). Environmental improvement of product supply chains: Proposed best practice techniques, quantitative indicators and benchmarks of excellence for retailers. Journal of Environmental Management, 15(4), 442-467. http://dx.doi.org/10.1016/j.jenvman.2012.05.021

Velázquez, L. E., Esquer, J., \& Munguía, N. E. (2011). Sustainable learning organizations. The Learning Organization, 18(1), 36-44. http://dx.doi.org/10.1108/09696471111095984

Walsh, J., \& Ungson, G. R. (1991). Organizational memory. Academy of Management Review, 16(1), 57-91. http://dx.doi.org/10.5465/AMR.1991.4278992

Yarahmadi, M., \& HigginS, P. G. (2012). Motivations towards environmental innovation: A conceptual framework for multiparty cooperation. European Journal of Innovation Management, 15(4), 400420. http://dx.doi.org/10.1108/14601061211272358

Yin. R. K. (2005). Estudo de caso: Planejamento e métodos (3a ed.). Porto Alegre: Bookman.

Zhang, B., Bi, J., Yuan, Z., Ge, J., Liu, B., \& Bu, M. (2008). Why do firm engage in environmental management? An empirical study in China. Journal of Cleaner Production, 16(10), 1036-1045. http://dx.doi.org/10.1016/j.jclepro.2007.06.016

Zhang, F., Rio, M., Romain, A., Zwolinski, P., Carrillo, T. R., Roucoules, L., Mercier-Laurent, E., \& Buclet, N. (2013). Toward a systemic navigation framework to integrate sustainable development into the company. Journal of Cleaner Production, 54(1), 199-214. http://dx.doi.org/10.1016/j.jclepro.2013.03.054 


\section{Dados dos Autores}

Rafael Ricardo Jacomossi

Rua Tamandaré, 688, 01525-000, Liberdade, São Paulo, SP, Brasil. E-mail: rjacomossi@fei.edu.br; rafaeljacomossi@gmail.com

Jacques Demajorovic

Rua Tamandaré, 688, 01525-000, Liberdade, São Paulo, SP, Brasil. E-mail: jacquesd@ fei.edu.br 